\title{
Study on Aerodynamic Characteristics of Supersonic Airfoil
}

\author{
Wentao Yong \\ Shanghai World Foreign Language Academy, Shanghai, China \\ Email: flenzoywt@163.com
}

How to cite this paper: Yong, W.T. (2019) Study on Aerodynamic Characteristics of Supersonic Airfoil. Modern Mechanical Engineering, 9, 13-19.

https://doi.org/10.4236/mme.2019.91002

Received: November 14, 2018

Accepted: January 29, 2019

Published: February 1, 2019

Copyright $\odot 2019$ by author(s) and Scientific Research Publishing Inc. This work is licensed under the Creative Commons Attribution International License (CC BY 4.0).

http://creativecommons.org/licenses/by/4.0/

\section{(c) (i) Open Access}

\begin{abstract}
With the invention of the aircraft, it has become much faster and larger than the original Wright Brothers aircraft. When the speed is high enough to cross the speed of sound, air conditions will be different than that in low speed due to the existence of shock wave. In this work, we introduce several numerical ways to analyze the performance of the airfoil when the speed is higher than the speed of sound. With these numerical methods, we analyzed the performance of diamond-shaped airfoil under different angles of attack and speed. With this data, engineers can choose a better airfoil to attain a lower drag coefficient as well as lift coefficient when designing a high-speed aircraft.
\end{abstract}

\section{Keywords}

Aerodynamic, Supersonic Speed, Diamond-Shape Airfoil, Drag Coefficient, Lift Coefficient

\section{Introduction}

For an aircraft, the airfoil is one of the most important components. The function of the airfoil includes: 1) generating lift to ensure flight and maneuverability meet the requirements specified by aircraft tactical technology; 2) ensuring the aircraft's lateral stability, maneuverability, take-off lift, and landing resistance; 3) installation of landing gear, engine, and weapon; 4) Loading fuel, ordnance, equipment, etc. Moreover, the structure of the airfoil needs to be well designed to satisfy aerodynamic requirements, weight, and maintenance requirements [1] [2].

The aerodynamic requirements: Wings are primarily used to generate lift. The aerodynamic characteristics of the wing are guaranteed by their shape parameters (string ratio $\lambda$, relative thickness $c$, sweep angle $\chi$, etc.), which have been determined simultaneously as the overall design. When designing the 
structure, the aerodynamic shape of the wing should satisfy the strength, rigidity and surface texture requirements (i.e. smoothness).

Weight requirements: When the shape, loading and connection of the airfoil are completed, the wing structure must meet the requirements of the uniform weight distribution. It is necessary to design a structure that meets the requirements of strength (i.e. static strength, dynamic strength and fatigue strength, etc.), stiffness and life expectancy while being as light as possible.

Use and maintenance requirements: It is required for the aircraft to be made in a way that is easy to inspect, maintain and repair. Inside the wing, there are often control system components, fuel, electrical, and hydraulic lines, etc. These systems and lines must be checked and adjusted frequently. When the entire fuel tank is arranged inside the wing, it must be inspected and maintained frequently to ensure the reliability of the seal on the fuel tank. The wing designed according to the safety principle of damage should be inspected periodically as the structure could affect flight safety. All of the parts of the aircraft that require inspection and maintenance should be easily accessible, and a certain number of openings must be set [3].

For the supersonic airfoil, the study should focus on aerodynamic performance because a well-designed aerodynamic airfoil can distribute the load uniformly as well as reduce air resistance to meet either economic or performance requirements. To study the supersonic aerodynamic characteristics of an aircraft, the calculation model is the supersonic airfoil, including two types-diamond-shaped airfoil and symmetric double-curved airfoil. The methods include the shock wave expansion method, the first approximation method, and the second approximation method. The goal is to calculate the pressure coefficient, lift coefficient and drag coefficient of the surface of the airfoil surface for a given inflow condition [4] [5].

\section{Methods}

If we know the wave-front Mach number $M_{1}$, pressure $p_{1}$ and outer corner $\delta$, the post-wave Mach numbers $M_{2}$ and $p_{2}$ can be obtained [6] [7].

Step 1:

Find the post-Mach number $M_{2}$ by the wave-front Mach number $M_{1}$ and the outer corner angle $\delta$ using the Newton iteration method and other methods to solve the following equation.

$$
\begin{aligned}
\delta= & {\left[\sqrt{\frac{\gamma+1}{\gamma-1}} \operatorname{arctg} \sqrt{\frac{\gamma-1}{\gamma+1}\left(M_{2}^{2}-1\right)}-\operatorname{arctg} \sqrt{M_{2}^{2}-1}\right] } \\
& -\left[\sqrt{\frac{\gamma+1}{\gamma-1}} \operatorname{arctg} \sqrt{\frac{\gamma-1}{\gamma+1}\left(M_{1}^{2}-1\right)}-\operatorname{arctg} \sqrt{M_{1}^{2}-1}\right]
\end{aligned}
$$

Step 2:

Determine post-wave pressure $p_{2}$ by using post-Mach number $M_{2}$.

$$
\frac{p_{01}}{p_{1}}=\left(1+\frac{\gamma-1}{2} M_{1}^{2}\right)^{\frac{\gamma}{\gamma-1}}
$$




$$
\frac{p_{02}}{p_{1}}=\left(1+\frac{\gamma-1}{2} M_{2}^{2}\right)^{\frac{\gamma}{\gamma-1}}
$$

Since the expansion wave is an isentropic process, $P_{01}=P_{02}$.

Through the above three formulas, $P_{2}$ can be obtained.

\subsection{Shock Wave Calculation}

First, confirm that you have the correct template for your paper size. This template has been tailored for output on the custom paper with the following measurements: $21 \mathrm{~cm}$ by $28.5 \mathrm{~cm}$. If the wave front Mach number $M_{1}$, pressure $p_{1}$ and inner corner $\delta$ are given, the post Mach number $M_{2}$ and post wave pressure $p_{2}$ can be obtained.

Step 1:

The shock wave angle $\beta$ is obtained by the wave front Mach number $M_{1}$ and the inner corner angle $\delta$.

$$
\operatorname{tg} \delta=\frac{M_{1}^{2} \sin ^{2} \beta-1}{\left[M_{1}^{2}\left(\frac{\gamma+1}{2}-\sin ^{2} \beta\right)+1\right] \cdot \operatorname{tg} \beta}
$$

This equation can be solved using a numerical method.

Step 2:

Find the post Mach number $M_{2}$ and the post-wave pressure $p_{2}$ by the wave front Mach number $M_{1}$ and the shock wave angle $\beta$.

$$
\begin{aligned}
& M_{2}^{2}=\frac{M_{1}^{2}+\frac{2}{\gamma-1}}{\frac{2 \gamma}{\gamma-1} M_{1}^{2} \cdot \sin ^{2} \beta-1}+\frac{\frac{2}{\gamma-1} M_{1}^{2} \cos ^{2} \beta}{M_{1}^{2} \cdot \sin ^{2} \beta+\frac{2}{\gamma-1}} \\
& \frac{p_{2}}{p_{1}}=\frac{2 \gamma}{\gamma+1} M_{1}^{2} \cdot \sin ^{2} \beta-\frac{\gamma-1}{\gamma+1}
\end{aligned}
$$

\subsection{Primary Approximation}

For the supersonic airfoil, the thickness is often thin, the curvature is small or even zero, and the flight angle of attack is also small. Thus, linearization can be adopted. The waves on the airfoil, including the Mach wave on the airfoil leading edge and trailing edge as well as the expansion wave, are estimated based on the wing flow Mach wave which is never disturbed.

$$
C_{p \text { wall }}= \pm \frac{2 \delta}{\sqrt{M_{\infty}^{2}-1}}= \pm \frac{2 \delta}{B}
$$

In the wind shaft coordinate system, when the folding angle $\delta$ is small, $\delta$ can be regarded as the tangent of the angle between the tangent of a point on the airfoil and the flow along the $\mathrm{x}$-axis, that is, the slope (i.e. $\mathrm{d} y / \mathrm{d} x$ ).

$$
C_{p}= \pm \frac{2}{B} \frac{\mathrm{d} y}{\mathrm{~d} x}
$$

After obtaining the airfoil surface pressure coefficient, the lift coefficient and the drag coefficient can be obtained by integration. 


\subsection{Secondary Approximation}

If the quadratic term of $\delta$ is retained in the expression of the pressure coefficient, a second approximation is obtained.

$$
\begin{aligned}
C_{p \text { wall }} & = \pm \frac{2 \delta}{\sqrt{M_{\infty}^{2}-1}}+\frac{(\gamma+1) M_{\infty}^{4}-4\left(M_{\infty}^{2}-1\right)}{2\left(M_{\infty}^{2}-1\right)^{2}} \delta^{2} \\
& = \pm \frac{2 \delta}{B}+\frac{(\gamma+1) M_{\infty}^{4}-4 B^{2}}{2 B^{4}} \delta^{2}
\end{aligned}
$$

Given the airfoil surface pressure coefficient, the lift coefficient and the drag coefficient can be obtained by integration [8]-[14].

\section{Results}

Experimental conditions: diamond-shaped airfoil, relative thickness $9 \%$, incoming Mach number 2.1. The results are obtained by a C program [15] (Figures 1-3 and Tables 1-3).

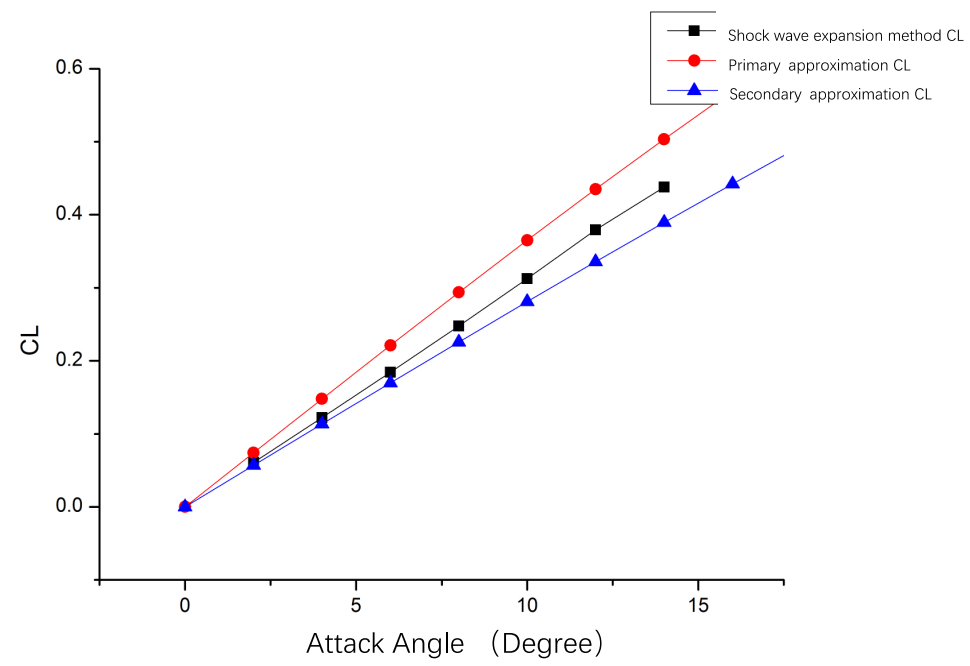

Figure 1. Graph of Lift Coefficient Measured by Three Methods.

Table 1. Lift Coefficient Measured by Three Methods.

\begin{tabular}{cccc}
\hline $\begin{array}{c}\text { Angle of Attack } \\
\text { (Degree) }\end{array}$ & $\begin{array}{c}\text { Shock wave } \\
\text { expansion method CL }\end{array}$ & $\begin{array}{c}\text { Primary } \\
\text { approximation CL }\end{array}$ & $\begin{array}{c}\text { Secondary } \\
\text { approximation CL }\end{array}$ \\
\hline 0 & 0.000000 & 0.000000 & 0.000000 \\
2 & 0.060874 & 0.074107 & 0.056813 \\
4 & 0.122157 & 0.147941 & 0.113482 \\
6 & 0.184264 & 0.221228 & 0.169861 \\
8 & 0.247616 & 0.293696 & 0.225806 \\
10 & 0.312594 & 0.365075 & 0.281174 \\
12 & 0.379151 & 0.435098 & 0.335821 \\
14 & 0.437991 & 0.503498 & 0.389605 \\
16 & & 0.570014 & 0.442385 \\
18 & & 0.634388 & 0.404019 \\
20 & & 0.696365 & 0.544370 \\
\hline
\end{tabular}




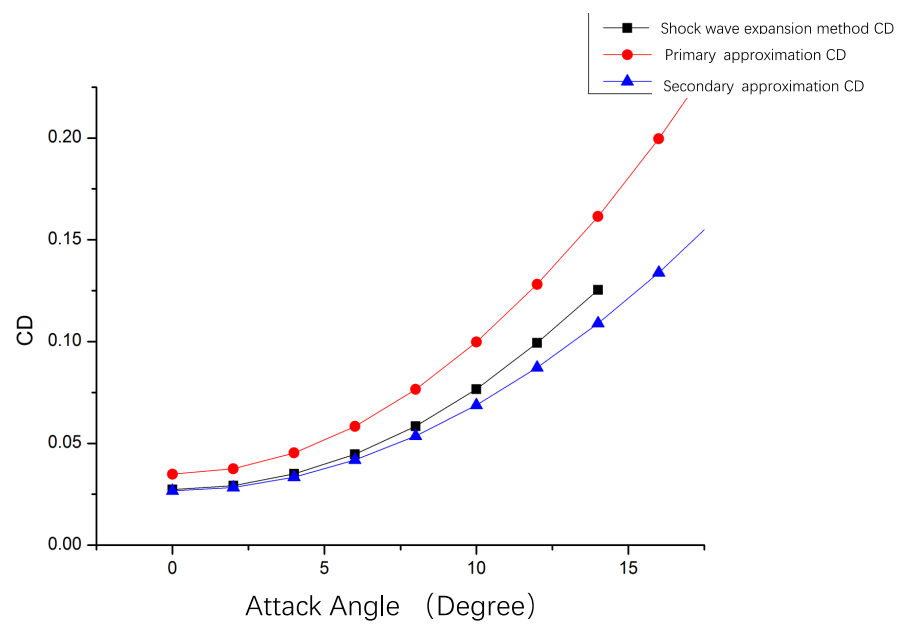

Figure 2. Graph of drag coefficient measured by three methods.

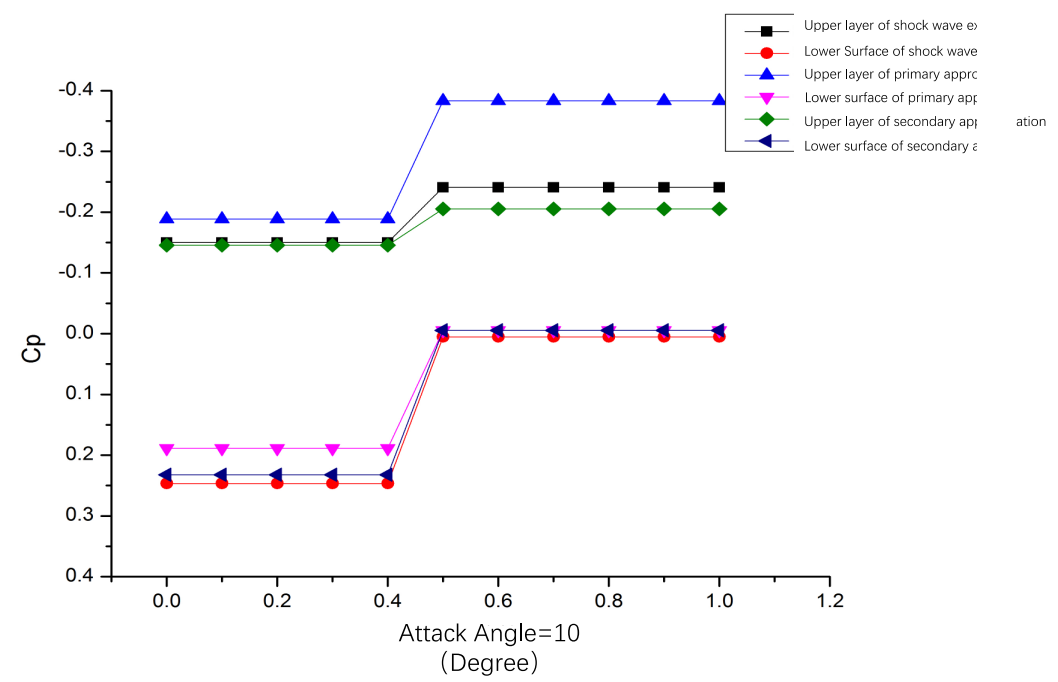

Figure 3. Graph of drag coefficient on upper layer and lower surface.

Table 2. Drag coefficient measured by three methods.

\begin{tabular}{cccc}
\hline $\begin{array}{c}\text { Angle of attack } \\
(\text { Degree })\end{array}$ & $\begin{array}{c}\text { Shock wave } \\
\text { expansion method CD }\end{array}$ & $\begin{array}{c}\text { Primary } \\
\text { approximation CD }\end{array}$ & $\begin{array}{c}\text { Secondary } \\
\text { approximation CD }\end{array}$ \\
\hline 0 & 0.027380 & 0.034903 & 0.026685 \\
2 & 0.029276 & 0.037511 & 0.028374 \\
4 & 0.035000 & 0.045328 & 0.033437 \\
6 & 0.044659 & 0.058335 & 0.041867 \\
8 & 0.058431 & 0.076501 & 0.053651 \\
10 & 0.076570 & 0.099780 & 0.068770 \\
12 & 0.099345 & 0.128116 & 0.087201 \\
14 & 0.125407 & 0.161440 & 0.108915 \\
16 & & 0.199669 & 0.133878 \\
18 & & 0.242710 & 0.162052 \\
20 & & 0.290457 & 0.193391 \\
\hline
\end{tabular}


Table 3. Table of drag coefficient on upper layer and lower surface.

\begin{tabular}{|c|c|c|c|c|c|c|}
\hline $\mathrm{X}$ & $\begin{array}{l}\text { Upper layer of } \\
\text { shock wave } \\
\text { expansion } \\
\text { method }\end{array}$ & $\begin{array}{l}\text { Lower surface } \\
\text { of shock wave } \\
\text { expansion } \\
\text { method }\end{array}$ & $\begin{array}{l}\text { Upper layer } \\
\text { of Primary } \\
\text { approximation }\end{array}$ & $\begin{array}{l}\text { Lower surface } \\
\text { of Primary } \\
\text { approximation }\end{array}$ & $\begin{array}{l}\text { Upper layer } \\
\text { of Secondary } \\
\text { approximation }\end{array}$ & $\begin{array}{l}\text { Lower surface } \\
\text { of Secondary } \\
\text { approximation }\end{array}$ \\
\hline 0 & -0.150196 & 0.246505 & -0.188934 & 0.188934 & -0.145707 & 0.232161 \\
\hline 0.1 & -0.150196 & 0.246505 & -0.188934 & 0.188934 & -0.145707 & 0.232161 \\
\hline 0.2 & -0.150196 & 0.246505 & -0.188934 & 0.188934 & -0.145707 & 0.232161 \\
\hline 0.3 & -0.150196 & 0.246505 & -0.188934 & 0.188934 & -0.145707 & 0.232161 \\
\hline 0.4 & -0.150196 & 0.246505 & -0.188934 & 0.188934 & -0.145707 & 0.232161 \\
\hline 0.5 & -0.240884 & 0.005204 & -0.383361 & -0.005493 & -0.205389 & -0.005457 \\
\hline 0.6 & -0.240884 & 0.005204 & -0.383361 & -0.005493 & -0.205389 & -0.005457 \\
\hline 0.7 & -0.240884 & 0.005204 & -0.383361 & -0.005493 & -0.205389 & -0.005457 \\
\hline 0.8 & -0.240884 & 0.005204 & -0.383361 & -0.005493 & -0.205389 & -0.005457 \\
\hline 0.9 & -0.240884 & 0.005204 & -0.383361 & -0.005493 & -0.205389 & -0.005457 \\
\hline 1 & -0.240884 & 0.005204 & -0.383361 & -0.005493 & -0.205389 & -0.005457 \\
\hline
\end{tabular}

\section{Discussion and Conclusion}

From the results, we can conclude the following:

1) When the angle of attack is $14^{\circ}$ degrees, the shock wave expansion method is not available because of the separation of shock wave. This phenomenon can be observed from the lift coefficient and drag coefficient map. Thus, the data when the angle of attack is greater than $14^{\circ}$ is not in the figure.

2) Although the lift coefficient and drag coefficient graph show that the three algorithms agree with the experimental results at $\alpha=10^{\circ}$, however, on the pressure map of $\alpha=10^{\circ}$ only the results obtained by the shock wave expansion method can match the experiment. The results of the anastomosis, first-order approximation, and pressure distribution along the string obtained by second-order approximation method are different from the experimental ones. The two approximation algorithms are different from the experiment at the leading edge and the trailing edge, but after integration for the lift coefficient. This error is inconspicuous. The reason for this may be that the first and second approximation algorithms consider the Mach number of the airfoil flow to be the same, omitting the need to apply the airfoil angle to the Mach number. The impact is that the results are significantly different than the experiment, that is, the compression is insufficient and the expansion is more than enough.

3) By comparing the diamond-shaped airfoil with the double-arc airfoil, it is clear that the shock wave expansion method can separate the shock wave at an angle of attack of about $14^{\circ}$, which invalidates the shock wave expansion wave method.

4) By comparing the diamond-shaped airfoil with the double-arc airfoil, when using the second-order approximation method, under the same conditions, the double-arc lift coefficient is greater than the lift coefficient of the diamond-shaped airfoil. 
5) By comparing the diamond-shaped airfoil with the double-arc airfoil, we've discovered that the first-order approximation method and second-order approximation method of the double-circular airfoil are closer to the study of the lift coefficient and the drag coefficient, while the diamond-shaped airfoil first-order approximation and the second approximation rule are different.

6) By comparing the diamond-shaped airfoil with the double-arc airfoil, when using the second-order approximation method, under the same conditions, when the angle of attack is less than $4^{\circ}$, the drag coefficient of the double-arc airfoil is smaller than that of the diamond-shaped airfoil; when it is greater than $4^{\circ}$, the drag coefficient of the double arc airfoil is greater than the drag coefficient of the diamond airfoil.

\section{Conflicts of Interest}

The author declares no conflicts of interest regarding the publication of this paper.

\section{References}

[1] Li, Z.N. (2010) Aircraft Structure Science. 2nd Edition, Beihang University Press, Beijing.

[2] Raymer, D. (2012) Aircraft Design: A Conceptual Approach. 5th Edition.

[3] Hicks, R.M. and Henne, P.A. (1978) Wing Design by Numerical Optimization. Journal of Aircraft, 15, 407-412. https://doi.org/10.2514/3.58379

[4] Fang, Z.P. (2005) Aeronautical Aircraft Flight Dynamics. Beihang University Press, Beijing.

[5] Qian, Y.J. (2004) Aerodynamics.

[6] Henne, P.A. (Ed.) (1990) Applied Computational Aerodynamics. American Institute of Aeronautics and Astronautics.

[7] Zheng, H.Y. (2012) Numerical Method.

[8] Rao, V.M., Behal, A., Marzocca, P. and Rubillo, C.M. (2006) Adaptive Aeroelastic Vibration Suppression of a Supersonic Airfoil with Flap. Aerospace Science and Technology, 10, 309-315. https://doi.org/10.1016/j.ast.2006.03.006

[9] Munk, M.M. (1950) The Reversal Theorem of Linearized Supersonic Airfoil Theory. Journal of Applied Physics, 21, 159-161. https://doi.org/10.1063/1.1699616

[10] Puckett, A.E. (1946) Supersonic Wave Drag of Thin Airfoils. Journal of the Aeronautical Sciences, 13, 475-484. https://doi.org/10.2514/8.11425

[11] Wakefield, G.H. (1970) U.S. Patent No. 3,497,163. U.S. Patent and Trademark Office, Washington, DC.

[12] Gazley, C. (1956) Linearized Solution for Heat Addition at the Surface of a Supersonic Airfoil.

[13] Wylly, A. (1952) A Second-Order Solution for an Oscillating Two-Dimensional Supersonic Airfoil. Journal of the Aeronautical Sciences, 19, 685-696. https://doi.org/10.2514/8.2430

[14] Wakefield, G.H. (1971) U.S. Patent No. 3,596,852. U.S. Patent and Trademark Office, Washington, DC.

[15] Tan, H.Q. (2017) C Program Design. $5^{\text {th }}$ Edition. 